\title{
RELIGIÃO E ESFERA PÚBLICA: O DISCURSO RELIGIOSO NO CONTEXTO DAS RELAÇÕES SOCIAIS E SUA RELAÇÃO COM A INTOLERÂNCIA E O PRECONCEITO
}

\section{ARTIGO ORIGINAL}

\author{
DRESCH, Paulo Cesar ${ }^{1}$
}

DRESCH, Paulo Cesar. Religião e esfera pública: 0 discurso religioso no contexto das relações sociais e sua relação com a intolerância e o preconceito. Revista Científica Multidisciplinar Núcleo do Conhecimento. Ano 04, Ed. 06, Vol. 09, pp. 105-114. Junho de 2019. ISSN: 2448-0959

\section{RESUMO}

Este trabalho pretende discorrer sobre as condições da formação dos valores morais e éticos que reinam em sociedade, sobretudo do ponto de vista socio-histórico-político no contexto das inter-relações estabelecidas sobre o aspecto de um discurso religioso no cerne das relações sociais. Partindo de pressupostos de construção de uma consciência coletiva, possibilitada pela imanência que a influência da religião exerce nos espaços públicos, as regras de convivência entre as pessoas são estabelecidas levando em conta aspectos de sua religiosidade, esta, intrinsecamente enraizada desde os primeiros traços de cultura humana. Com fundamento no campo da filosofia

\footnotetext{
${ }_{1}$ Pós-Graduado Lato Sensu em História Social pela Universidade Federal do Espírito Santo (UFES). Pós-Graduado Lato Sensu em Ciências da Religião pela Universidade Cândido Mendes (UCAM). Licenciado em História pela Universidade Estácio de Sá (UNESA). Graduado em Música pela Faculdade de Música do Espírito Santo (FAMES). Graduando em Filosofia pela Universidade Federal do Espírito Santo (UFES). Docente de História na rede municipal e estadual de ensino do Estado do Espírito Santo. Foi professor voluntário de História Geral no Projeto Afirmação - rede de cursinhos populares.
} 
política de John Rawls, da teoria crítica e do pragmatismo de Jürgen Habermas, assim como o que Karem Armstrong sugeriu quando de sua investigação acerca da influência sociocultural legada pelas três religiões abraâmicas, a análise salientará que a hegemonia de determinada religiosidade nos espaços públicos, pode influenciar e fomentar a proliferação de intolerância e preconceito, nas instituições, na família, na escola, nas decisões políticas, entre outras, reforçando atitudes fundamentalistas. Desse modo, o conceito de alteridade, desde uma perspectiva que contemple as distintas formas de manifestação religiosa, com vistas a permitir e fomentar o pluralismo e o diálogo inter-religioso, pode proporcionar uma pacífica coexistência entre as diferentes formas de religiosidade, ou pelo menos salientar a importância do debate na sociedade.

Palavras-chave: Diálogo inter-religioso, valores, controle social, pluralismo, intolerância.

\section{INTRODUÇÃO}

Pensar uma sociedade onde não haja preconceito e/ou intolerância em relação ao diferente, numa convivência pacífica entre as distintas formas de religiosidade no que se refere ao respeito às minorias, com fulcro na racionalidade para a coexistência da diversidade religiosa, continua sendo um desafio na atualidade assim como nos primórdios da civilização. A religiosidade predominante no imaginário social, preenche os espaços público e privado com vistas a proliferação de ideias que fundamentam ideologias que abarcam apenas uma visão de mundo hegemônica. Isso permite a propagação de fundamentalismos que, muitas das vezes, reflete nas decisões políticas e contribui para o fomento da intolerância e do preconceito, atingindo e ultrapassando o âmbito da esfera público-privada.

Ainda que atual legislação brasileira deixa clara a laicidade do Estado, bem como a total liberdade de escolha individual da religião, o pensamento ideológico religioso que prevalece é unilateral, onde o Estado se apropria desse pensamento para formar uma consciência coletiva alinhada com seus interesses políticos e econômicos. A 
construção de uma consciência ética e moral coletiva, dentro da perspectiva de um pensamento religioso hegemônico, é usada como instrumento de controle social pelas classes dominantes a fim de sustentar o status quo de privilégios em detrimento da exploração das classes dominadas. Essa visão materialista histórico dialética, permite considerarmos uma profunda relação entre dominados e dominantes no contexto socio-histórico-político do ponto de vista das formas de alienação e subjugação em face dos interesses de uma minoria.

Sendo assim, as instituições sociais, políticas e econômicas, são formadas por pessoas que pensam e agem conforme suas convicções ideológicas, consubstanciando o pensamento que predomina na sua formação cultural e sócio afetiva, bem como de sua construção religiosa. Ainda que a visão ideológico-religiosa predominante tenha como referência as distintas interpretações da religião Cristã, dentre católicas, protestantes, evangélicos, espíritas ou ainda as religiões afrobrasileira, a gênese que permeia o cerne da construção de uma moral e de uma ética, tem em comum aspectos intrinsecamente enraizados culturalmente numa mesma ótica dogmática. Ou seja, aquela em que os preceitos legais são, muitas das vezes, evocados a partir de regras ou doutrinas utilizadas no contexto religioso.

Logo, o presente trabalho analisará os efeitos que essa perspectiva pode suscitar na sociedade, tendo como supedâneo o pensamento de alguns autores, tais como John Rawls, notadamente em Uma Teoria da Justiça (1971) e O Liberalismo Político (1993), onde ele discorre sobre a noção de consenso sobreposto, com vistas a examinar qual o tipo de contribuição que as pessoas que possuem crenças religiosas podem oferecer para o debate público no contexto de questões constitucionais e de justiça básica. A análise ainda se sustentará sob o ponto de vista de autores como Habermas, Karen Armstrong, entre outros, os quais discorreram sobre o papel das religiões nos espaços público-privados e sua contribuição para o fomento das relações imbricadas no que diz respeito à intolerância e o preconceito.

Dessa forma, é possível haver um diálogo inter-religioso partindo de pressupostos entre o dualismo premente na sociedade, ou seja, o pluralismo religioso e a forte 
marca de um inconsciente religioso hegemônico imanente enraizado desde sua gênese colonial? Podemos conviver com distintos pensamentos sobre questões complexas como aborto, liberdade sexual, uso ou não de drogas, crença ou descrença religiosa? É exequível convivermos pacificamente sem o estigma do preconceito e da intolerância face às distintas formas de manifestações religiosas? Para responder estas questões, analisaremos, entre outras coisas, o desvelamento do sentido de razão pública descrita no pensamento de John Rawls, assim como o do conceito de consenso sobreposto. As obras de pensadores como Pierre Bourdieu, Habermas, Karen Armstrong, entre outros, fornecerão aporte teórico-epistemológico para uma melhor clareza das questões pertinentes.

\section{O PENSAMENTO RELIGIOSO NO CERNE NA SOCIEDADE CONTEMPORÂNEA}

A formação da sociedade brasileira, além das peculiares características sóciohistórico-políticas, foi alicerçada sob os pilares de forte presença religiosa desde sua gênese colonial, incialmente na perspectiva hegemônica da tradição Católica Apostólica Romana oficializada pelo Estado até a promulgação da Constituição de 1891. Há que considerar também uma incipiente introdução do protestantismo de vertente Luterana e Calvinista ainda no período colonial com Heliodoro Heoboano ${ }^{[2]}$ em São Vicente, sobretudo com a tentativa de colonização do Brasil por huguenotes, bem como na esteira da missão francesa enviada por João Calvino quando da criação da França Antártica ainda no século XVI. Por outro lado, urge avultar também que a escravidão africana exerceu forte influência na formação identitária cultural e religiosa com a introdução de elementos dessas sociedades, permitindo um sincretismo religioso na construção de uma cultura religiosa afro-brasileira.

A partir do início do século $X X$, com a chegada de protestantes de vertente pentecostal, um novo cenário começou a despontar. Se já havia condições para o fomento de preconceito e da intolerância, esse quadro exacerbou ao encontrar um ambiente propício em face de uma população semianalfabeta e carente de recursos econômicos básicos. Com o advento do neopentecostalismo a partir do final da

Disponível em: https://www.nucleodoconhecimento.com.br/ciencia-da-religiao/religiao-e-esferapublica 
década de 1970, distintas formas de representação da religiosidade foram tomando os espaços público e privado, proporcionando novas formas de intolerância e preconceito marcados por tensões e ambiguidades em relação às conveniências materiais e simbólicas dela decorrentes, oriundas da lógica marxista de acumulação de capital em detrimento da exploração por meio da mais valia[3].

O sistema de produção e circulação de bens simbólicos define-se como sistema de relações objetivas entre diferentes instâncias definidas pela função que cumprem na divisão do trabalho de produção, de reprodução e de difusão de bens simbólicos. [...] o campo da indústria cultural especificamente organizado com vistas à produção de bens culturais destinados a não-produtores de bens culturais (“o grande público") que podem ser recrutados tanto nas frações não-intelectuais das classes dominantes ("o público cultivado") como nas demais classes sociais. (BOURDIEU, 2007, p. 105)

Sendo assim, a religião, notadamente a de vertente Cristã protestante neopentecostal, estruturada em torno da lógica do pensamento econômico liberal, assume características de uma empresa com fins lucrativos. Líderes e membros dessas instituições religiosas ocupam os espaços públicos na política e na justiça, fazendo deles a extensão de seus ideais de mundo moral e ético, resinificando costumes e crenças de uma sociedade que viveu na Idade do Bronze, os quais se fundamentam em argumentos dogmáticos arcaicos em contraposição a uma razão de justiça pensada na racionalidade, pluralidade e no bem comum. Imediatamente, há uma proliferação crescente de influências políticas de ortodoxia religiosa na esfera pública em contraposição aos avanços da ciência nos mais diversos campos do conhecimento humano. (HABERMAS, 2007)

Do ponto de vista dessa perspectiva unilateral de pensamento, agentes oriundos dessas comunidades religiosas, adquiriram grande destaque nos diversos campos da esfera pública, substancialmente na política. Ocuparam espaços no rádio, na televisão, entre outros, ampliando assim a capacidade de influenciar legiões de um

Disponível em: https://www.nucleodoconhecimento.com.br/ciencia-da-religiao/religiao-e-esferapublica 
"rebanho desorientado" (CHOMSKY, 2014), que, desprovidas de um certo nível de conhecimento, em especial de um pensamento crítico e reflexivo, são cooptadas com relativa facilidade. A partir desse ponto, o discurso religioso assume características teológicas de prosperidade, encontrando terreno numa massa de desvalidos economicamente e ávidos em conseguir bens materiais, diuturnamente bombardeadas pela "indústria cultural" (Adorno e Horkheimer, 1985), resultante de uma sociedade adestrada para o consumo.

Em nossa sociedade, dominada pela mídia, a esfera pública serve, em primeiro lugar, como espaço de auto-apresentação daqueles que se destacam na sociedade por uma razão ou por outra. A finalidade das aparições em público reside na visibilidade ou na notoriedade. (HABERMAS, 2007, p. 17)

Nesse aspecto, a visão de consumo e autossatisfação individualizada da contemporaneidade, construída sob a ótica do capitalismo, transcende os espaços público-privado, onde o Estado, que também sofre a influência da religião, se apropria dessa retórica com vistas a fortalecer o controle social sobre uma população em crescente desigualdade, insegurança social e rejeição cultural.

\section{INTOLERÂNCIA COMO INFERÊNCIA DO DISCURSO RELIGIOSO E PERSPECTIVAS DE UMA PLURALIDADE CONSENSUAL}

Na obra Em nome de Deus (2001), a especialista em religião Karen Armstrong investigou os movimentos fundamentalistas constituintes nas três religiões abraâmicas (Judaísmo, Cristianismo e Islamismo), notadamente a partir do final do século XV com a expulsão dos muçulmanos de Al-andaluz pelos reis católicos Fernando e Isabel, onde àqueles, desde o século VIII, haviam estabelecido independência política na Península Ibérica sob o domínio do Califado Omíada. Segundo a autora, o fundamentalismo se consuma quando a religião rejeita ou desconhece conceitos de pluralismo, democracia, tolerância religiosa, liberdade de 
expressão e laicidade, concepções estas que perfazem a antítese dos "[...] valores mais positivos da sociedade moderna". (ARMSTRONG, 2001, p. 6)

Já John Rawls, na obra Uma Teoria da Justiça, sustenta que temas ligados às questões religiosas e de dogmas, não devem ser considerados quando da discussão sobre justiça de qualquer sistema constitucional. Para ele, não há como haver um diálogo racional quando as opiniões são refletidas a partir de crenças e/ou em dogmas. O conceito de "justiça como equidade", defendida por este filósofo, favorece "[...] fortes argumentos a favor da liberdade de consciência igual". (RAWLS, 2000, p. 229)

Sendo assim, o que Rawls orienta, se consubstancia em uma prática igualitária que permite um certo consenso das relações sociais na sociedade.

Partirei do pressuposto de que esses argumentos podem ser generalizados de maneiras adequadas para defender o princípio de liberdade igual. Pois, as partes têm boas razões para adotar esse princípio. É óbvio que essas considerações também são importantes na justiça da prioridade da liberdade. Da perspectiva da convenção constituinte, esses argumentos levam à escolha de um regime que garante a liberdade moral, a liberdade de pensamento e de fé, e de prática religiosa, embora essa última, como de costume, possa ser regulada pelo interesse do Estado da segurança e da ordem públicas. (RAWLS, 2000, p. 229-230)

Logo, para Rawls o que é importante para determinar que uma sociedade conviva de forma pacífica e justa, são as ordenações de princípios que objetivem estabelecer os reais direitos e deveres dos indivíduos, propondo os fundamentos para dirimir conflitos prementes nas sociedades plurais e complexas. Por seu turno, o princípio da equidade demonstra ser esse o caminho que tenciona ordenar as relações sociais. Esse princípio, segundo o autor, reconhece uma estrutura básica da sociedade por meio de suas principais instituições, as quais se organizariam de forma a permitir vantagens 
que resultariam de uma cooperação social, pois ele entende que a sociedade é um sistema cooperativo que traz benefícios àqueles que participam dela.

Sem embargo, a religião tem como pressuposto um discurso sustentado em sua visão de mundo. Ou seja, um mundo onde, muita das vezes, conceitos como liberdade e justiça social são vistos como entrave, consoante sua perspectiva dogmática e fundamentalista. Essa visão, todavia, pode fomentar a proliferação de intolerância na sociedade, uma vez que se baseia em princípios regidos por institutos dogmáticos unilaterais e exclusivistas, onde questões como aborto e homossexualismo, por exemplo, são veementemente rejeitados e sem perspectiva de espaço para que haja uma discussão lógica e racional.

Nesse contexto, o Estado, representado por agentes da sociedade, muita das vezes se apropria do discurso religioso para legitimar suas convicções e seu domínio, sobretudo em face de seus interesses ou dos interesses de uma classe. O arbítrio de um único pensamento em detrimento dos demais numa sociedade plural, é o que faz surgir intolerâncias e preconceitos. Consequentemente, Rawls em sua outra obra $O$ Liberalismo Político, defende a ideia de um "consenso sobreposto" de doutrinas amplas razoáveis. O cerne de seu pensamento diz respeito a uma concepção de justiça política como sendo um tipo universal ou coletivo que abarque as distintas concepções abrangentes de bem razoáveis da sociedade, onde a idealização de justiça como equidade possibilitaria haver estabilidade pelas razões corretas. (RAWLS, 2000)

De outro modo, o conceito de consenso sobreposto em Rawls, numa perspectiva que contemple uma convivência pacífica numa sociedade plural como a brasileira, facilitaria a diminuição da intolerância e do preconceito contra seguimentos sociais, sobretudo minoritários: homossexuais, ateus, mulheres, movimentos sociais de espectro político à esquerda, entre outros. O cerne da questão rawlsiana, está na aceitação e/ou objetivação de uma "cooperação social", tendo em vista que traria vantagens à sociedade que dela participasse. Ele ainda discorre que as sociedades democráticas liberais e contemporâneas, compartilham distintas concepções 
abrangentes de bens, especialmente tendo as concepções religiosas como arquétipos, assim como as concepções políticas, notadamente porque:

Como dissemos antes (I:2.6), essa pluralidade razoável de doutrinas conflitantes e incomensuráveis é vista como um produto característico da razão prática no decorrer do tempo sob instituições livres e duradouras. [...] nenhuma doutrina abrangente é apropriada enquanto concepção política para um regime constitucional. (RAWLS, 2000, p. 181)

Sem demora, para que uma sociedade possa desfrutar de um ambiente onde as práticas de intolerância e preconceito não se sustentem, é plausível que haja uma condução política baseada em direitos e deveres constitucionalmente aceitos pelos cidadãos e que subsidiem a conduta destes nas esferas público-privadas, o que para Rawls se concretizaria a partir de uma coexistência plural de "doutrinas razoáveis". (RAWLS, 2000) Nisso ele estabelece que não há necessidade de usar o poder político para impor uma verdade única, uma vez que a razoabilidade de distintas doutrinas, por si só, conduziria ao bem comum e proporcionaria um cenário de estabilidade e cooperação política e social, pormenorizado em termos essenciais sob a égide de um consenso sobreposto de doutrinas abrangentes e razoáveis, (RAWLS, 2000) tendo em vista que,

[...] procura uma concepção política de justiça que, assim esperamos, possa conquistar apoio de um consenso sobreposto que abarque as doutrinas religiosas, filosóficas e morais razoáveis de uma sociedade regulada por ela. A conquista desse apoio, permitirá responder a nossa segunda questão fundamental: como os cidadãos, que continuam profundamente divididos em relação às doutrinas religiosas, filosóficas e morais, mantém, apesar disso, uma sociedade democrática, justa e estável? (RAWLS, 2000, p. 52) 
Nesse aspecto, Rawls, não obstante, espera que abandonemos o que ele chama de "visões filosóficas e morais abrangentes" (RAWLS, p. 52), no sentido de pensarmos uma sociedade onde os princípios e valores sejam estabelecidos constitucionalmente, na esteira de permitir que todos os cidadãos possam desfrutar de uma mesma consciência objetiva que os oriente para uma convivência pacífica no que diz respeito à tolerância religiosa, mesmo sob a égide de uma pluralidade de doutrinas. Dessa forma, haveria espaço para um diálogo inter-religioso como forma de dirimir questões de intolerância e preconceito que, por conseguinte, evitaria as disputas por motivações religiosas.

\section{CONSIDERAÇÕES FINAIS}

Todas sociedades e em todos os espaços e tempos da história humana, construíram sua moral, ética, costumes e sua política a partir também de suas crenças e práticas religiosas. Sobre elas alicerçaram seu modo de vida, sua conduta, disputaram espaços, aprovaram seus líderes políticos, promoveram genocídios, assim como subjugaram outros povos. Sob esse prisma, discutirmos aspectos de intolerância e preconceito motivados por questões religiosas, especialmente no atual estágio de desenvolvimento socio-histórico-político, posto que ainda asseveram nas sociedades ainda que democráticas, faz-se necessário, vez que pululam e causam estragos sócio psíquicos, transcendendo as esferas público-privadas.

Consequentemente, levando em consideração o pensamento rawlsiano, as relações sociais, desde uma perspectiva que abarque concepções políticas de justiça discutidas à luz de uma racionalidade após profunda e cuidadosa reflexão, pode ser o caminho para dirimir conflitos no que diz respeito à intolerância e o preconceito por motivos de crença e/ou dogmas religiosos. O pluralismo de ideias, ainda que divergentes, é plausível em sociedades democráticas desde que assistidos e confirmados por uma concepção política "correta de verdades dos julgamentos morais." (RAWLS, 2000, p. 176) 
Dessa forma, apesar de haver na sociedade uma pluralidade de crenças distintas, bem como profundas divisões doutrinárias religiosas, filosóficas e morais, que muitas das vezes coloca em choque os cidadãos por meio de disputas nos espaços públicoprivados, a estabilidade, consoante a perspectiva rawlsiana, pode ser atingida com base numa unidade social de um consenso sobreposto de doutrinas abrangentes e razoáveis, ainda que com pontos de vistas singulares.

\section{REFERÊNCIAS}

ADORNO, Theodor W. e HORKHEIMER, Max. Dialética do Esclarecimento. Tradução: Antônio de Almeida. Jorge Zahar Editor Ltda. Rio de Janeiro, 1985.

ARENDT, Hannah. Origens do totalitarismo. Tradução: Roberto Raposo. Companhia das Letras. 3ª reimpressão. São Paulo, 1998.

ARMSTRONG, Karen. Em nome de Deus: o fundamentalismo no judaísmo, no cristianismo e no islamismo. Tradução Hildegard Feist. Editora Schwarcz LTDA. São Paulo, 2009.

. Uma história de Deus. Editora Schwarcz S.A. São Paulo, 2012.

BERGER, Peter L. O Dossel Sagrado: elementos para uma teoria sociológica da religião. Trad. José Carlos Barcelos. Editoria Paulinas. São Paulo, 1985.

BOURDIEU, P., A economia das trocas simbólicas. 6ª edição. Editora Perspectiva S.A. São Paulo, 2007.

CHOMSKY, Noam. MÍDIA: propaganda política e manipulação. Tradução: Fernando Santos. Martins Fontes. São Paulo, 2014.

DURKHEIM, Émile. Formas elementares da vida religiosa: o sistema totêmico na Austrália. Tradução Joaquim Pereira Neto. São Paulo: Paulinas, 1999. 
HABERMAS, Jurgen. Entre Naturalismo e religião: estudos filosóficos. Trad. Flávio Beno Siebeneicheler. Rio de Janeiro: Tempo Brasileiro, 2007.

IBGE: Censos Demográficos de 1980, 1991 e 2000.

JUNG, Carl Gustav. Psicologia e religião. tradução do Pe. Dom Mateus Ramalho Rocha; revisão técnica de Dora Ferreira da Silva. — Petrópolis: Vozes, 1978.

MARX, K.; ENGELS, F. A ideologia alemã. Tradução de C. Jardim e Eduardo e E. L. Nogueira. 4. ed., Portugal: Presença / São Paulo: Martins Fontes, 1980.

MARX, Karl. Crítica da Filosofia do Direito de Hegel. In: Sobre a Religião. Lisboa: Edições 70, 1975, p.47-49.

MASSENZO, Marcelo. História das religiões na cultura moderna. Editora Hedra LTDA. São Paulo, 2005.

MÉSZÁROS, István. A teoria da alienação em marx. Tradução de Isa Tavares. São Paulo: Boitempo, 2006.

RAWLS, John. Uma Teoria da Justiça. Trad. Almiro Pisetta e Lenita M. R. Esteves. Martins Fontes, São Paulo, 2000.

O Liberalismo Político. Trad. Dinah de Abreu Azevedo. $2^{\mathrm{a}}$ edição. Editora Ática. São Paulo, 2000.

VOLTAIRE (François-Marie Arouet). Tratado sobre a tolerância. Tradução: Paulo Neves, $2^{\underline{a}}$ edição, Martins Fontes. São Paulo, 2000.

2. Primeiro luterano a chegar ao Brasil em 1532, filho de um amigo de Lutero, que aportou em São Vicente.

3. Termo utilizado por Karl Marx na obra O Capital, Volume I, Parte III, Capítulo VII, Processo de Trabalho e Processo de Produção de Mais Valia, Secção 2. A mais valia é um conceito da sociologia adotado por Karl Marx (1818-1883) no século XIX,

Disponível em: https://www.nucleodoconhecimento.com.br/ciencia-da-religiao/religiao-e-esferapublica 
o qual está relacionado com a força de trabalho, o tempo de realização e o lucro obtido.

Enviado: Janeiro, 2019

Aprovado: Junho, 2019.

$\mathrm{RC}: 32774$

Disponível em: https://www.nucleodoconhecimento.com.br/ciencia-da-religiao/religiao-e-esferapublica 